\title{
The ERECTA Receptor-Like Kinase Regulates Cell Wall-Mediated Resistance to Pathogens in Arabidopsis thaliana
}

\author{
Clara Sánchez-Rodríguez, ${ }^{1}$ José Manuel Estévez, ${ }^{2}$ Francisco Llorente, ${ }^{1}$ Camilo Hernández-Blanco, \\ Lucía Jordá, ${ }^{1}$ Israel Pagán, ${ }^{1}$ Marta Berrocal, ${ }^{1,2}$ Yves Marco, ${ }^{3}$ Shauna Somerville, ${ }^{2}$ and Antonio Molina ${ }^{1}$ \\ ${ }^{1}$ Centro de Biotecnología y Genómica de Plantas (UPM-INIA), Departamento Biotecnología, Campus Montegancedo \\ Universidad Politécnica de Madrid, E-28223-Pozuelo de Alarcón (Madrid), Spain; ${ }^{2}$ Carnegie Institution for Science, \\ Department of Plant Biology, Stanford, CA, 94305, U.S.A.; ${ }^{3}$ Laboratoire de interactions Plantes-Microorganismes, \\ CNRS-INRA, Chemin de Borde Rouge - BP 27, 31326 Castanet Tolosan Toulouse, France
}

Submitted 29 September 2008. Accepted 24 March 2009.

Some receptor-like kinases (RLK) control plant development while others regulate immunity. The Arabidopsis ERECTA (ER) RLK regulates both biological processes. To discover specific components of ER-mediated immunity, a genetic screen was conducted to identify suppressors of erecta (ser) susceptibility to Plectosphaerella cucumerina fungus. The ser 1 and $\operatorname{ser} 2$ mutations restored disease resistance to this pathogen to wild-type levels in the er-1 background but failed to suppress er-associated developmental phenotypes. The deposition of callose upon $P$. cucumerina inoculation, which was impaired in the $e r-1$ plants, was also restored to near wild-type levels in the ser er-1 mutants. Analyses of $e r$ cell walls revealed that total neutral sugars were reduced and uronic acids increased relative to those of wild-type walls. Interestingly, in the $\operatorname{ser}$ er-1 walls, neutral sugars were elevated and uronic acids were reduced relative to both $e r-1$ and wild-type plants. The cell-wall changes found in $e r-1$ and the ser er-1 mutants are unlikely to contribute to their developmental alterations. However, they may influence disease resistance, as a positive correlation was found between uronic acids content and resistance to $P$. cucumerina. We propose a specific function for $E R$ in regulating cell wall-mediated disease resistance that is distinct from its role in development.

The activation of plant and animal innate immunity systems involves a specific detection of microbe-associated molecular patterns (MAMPs) by different sets of host pattern-recognition receptors (PRR) (Ausubel 2005; Bittel and Robatzek 2007; Dangl and Jones 2001; Nürnberger and Brunner 2002). Several

Current address of C. Sánchez-Rodríguez: Max-Planck Institute for Mol. Plant Physiology, Am Muehlenberg 2, 14476 Potsdam, Germany.

Current address of J. M. Estevez: Departamento de Fisiología, Biología Molecular y Celular, Facultad Ciencias Exactas y Naturales, IFIByNECONICET, Universidad Buenos Aires, Pabellón 2, Ciudad Universitaria, Buenos Aires, Argentina.

Current address of S. Somerville: Energy Biosciences Institute, University of California, Berkeley, 94720, U.S.A.

Corresponding author: Antonio Molina; E-mail: antonio.molina@upm.es; Telephone: +(34) 913364552; Fax: +(34) 917157721

* The $\boldsymbol{e}$-Xtra logo stands for "electronic extra" and indicates that one supplementary table and five supplementary figures are published online. members of the plant leucine-rich repeat (LRR) receptor-like kinase (RLK) family, such as FLS2 and EFR, have been found to function as PRR (Gomez-Gomez et al. 2001; Shiu et al. 2004; Song et al. 1995; Zipfel et al. 2006). The immune responses mediated by these receptors can be modulated by additional RLK. For example, BAK1 (BRI1-asociated kinase 1) regulates FLS2 function through the formation of MAMPinduced RLK complexes (Chinchilla et al. 2007). Additional RLK play relevant roles in plant immunity, although their exact modes of action have not been elucidated. For example, the ERECTA (ER) LRR RLK is required for resistance in Arabidopsis to the soilborne bacterium Ralstonia solanacearum 14-25, the necrotrophic fungus Plectosphaerella cucumerina, and the damping-off oomycete Phythium irregulare, as er mutant alleles (e.g., er-1) are more susceptible to these pathogens than wild-type plants (Adie et al. 2007; Godiard et al. 2003; Llorente et al. 2005). Also, Arabidopsis BAK1 has been shown to regulate resistance to necrotrophic fungi by negatively controlling cell-death progression upon pathogen infection (He et al. 2007; Kemmerling et al. 2007).

In addition to their functions in immunity, LRR RLK control different plant cell growth and developmental processes (Becraft 2002; Hématy and Höfte 2008). For instance, BAK1 participates in brassinosteroid-mediated signaling by forming heterodimeric complexes with BRI1, a LRR RLK for the plant hormone brassinosteroid ( $\mathrm{Li}$ et al. 2002). The ER protein regulates inflorescence architecture, lateral organ shape, ovule development, stomatal patterning, and transpiration efficiency through its genetic interaction with two closely related paralogs (ERL1 and ERL2) and the genes TMM and EPF1 encoding, respectively, a receptor-like protein (RLP) and a peptide (Hara et al. 2007; Masle et al. 2005; Pillitteri et al. 2007; Shpak et al. 2003, 2004, 2005; Torii et al. 1996). The inflorescence of er mutants forms flattened floral bud clusters due to a reduction of internodal and pedicel elongation, which produces shorter siliques than in wild-type plants (Shpak et al. 2004, 2005; Torii et al. 1996). Also, genetic interactions between ER and genes controlling different developmental and hormone-mediated pathways have been described (Fridborg et al. 2001; Mele et al. 2003). The molecular bases of this double functionality in immunity and development processes of some RLK such as BAK1 and ER remains elusive.

In contrast to the well-characterized ER-mediated developmental signaling pathway, relatively few genetic elements of ER-mediated immunity to necrotrophic and soil-borne patho- 
gens have been identified (Adie et al. 2007; Godiard et al. 2003; Llorente et al. 2005). Resistance to these types of pathogens is often genetically complex in Arabidopsis and depends on the precise regulation of the ethylene (ET), jasmonic acid (JA), salicylic acid (SA) and abscisic acid (ABA) signaling pathways (Adie et al. 2007; Berrocal-Lobo et al. 2002; Hernández-Blanco et al. 2007; Thomma et al. 1999). Recent genetic analyses also showed that variation in plant wall composition results in altered disease resistance responses in a number of plant-pathogen combinations. Thus, the irregular xylem (irx) mutants impaired in cellulose synthase (CESA) subunits (AtCESA4 [IRX5], AtCESA7 [IRX3], and AtCESA8 [IRX1]) required for secondary cell-wall formation, and the prcl (procuste 1) and ixrl/cevl (isoxaben resistant; constitutive expression of VSP) mutants, which are defective, respectively, in the CESA6 and CESA3 subunits required for primary cell-wall formation, showed enhanced resistance to different necrotrophic, biotrophic, and soilborne pathogens (Ellis and Turner 2001; Hernández-Blanco et al. 2007). Interestingly, the the1 (theseus 1) mutant was isolated as a suppressor of the developmental alterations caused by the prcl and elil mutations, leading the authors to suggest that THE1 (a member of CrRLK1L family of RLK) may act as a cell-wall integrity sensor similar to those described in yeast (Hématy et al. 2007). Additional RLK from the CrRLK1L and the wall-associated
A
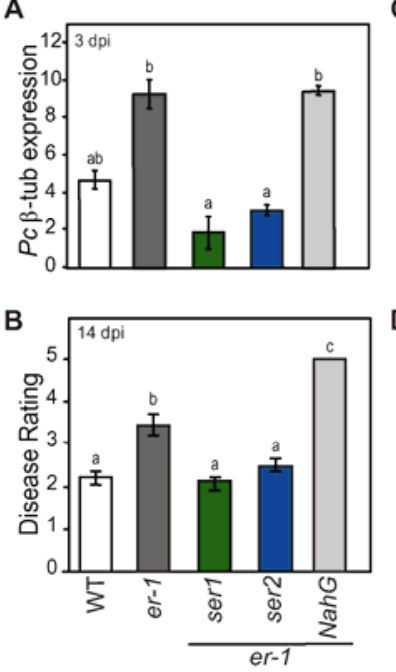

C

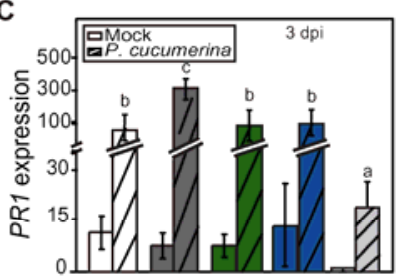

D

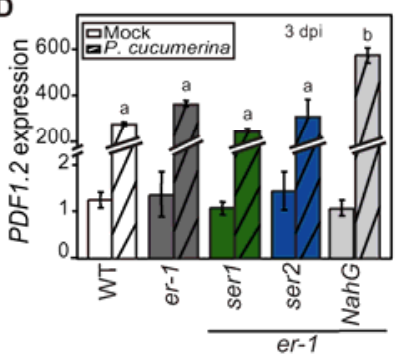

Fig. 1. The ser mutants suppressed er susceptibility to Plectosphaerella $\mathrm{cu}$ cumerina and restored disease resistance to wild-type levels. A, P. сисиmerina growth in wild-type (La-0, white bar), er-1 (dark gray bar), serl er-1 (green bars), and ser 2 er- 1 (blue bars) plants at 3 days postinoculation (dpi) with $P$. cucumerina at the rate of $4 \times 10^{6}$ spores $/ \mathrm{ml}$. Fungal growth was quantified by quantitative reverse transcriptase polymerase chain reaction (qRTPCR) using RNA samples from inoculated leaves harvested at 3 dpi. Specific primers of $P$. cucumerina $\beta$-tubulin and Arabidopsis ubiquitin genes were used for qRT-PCR. Values are represented as fold increase in expression compared with the genotype showing the lowest expression level. Data correspond to the average ( \pm standard error) of two replicates. B, Average disease rating (DR \pm standard deviation) of the indicated genotypes at 14 dpi. DR varies between 0 (no symptoms) and 5 (dead plants). The salicylic aciddeficient $N a h G$ er-1 plants (light gray bar) show enhanced susceptibility to this fungus (Llorente et al. 2005). Data are from one of four independent experiments that gave similar results. $\mathbf{C}$ and $\mathbf{D}$, Expression of PRI (C) and PDF1-2a (D) in wild-type, er-1, er-1 serl, er-1 ser2, and NahG er-1 plants. Total RNA was extracted from mock-inoculated (solid bars) and inoculated (striped bars) plants at 3 dpi. The transcript levels of $P R 1$ and PDF1-2a were quantified by quantitative reverse transcriptase polymerase chain reaction. Values were normalized to plant ubiquitin levels and are represented as the fold increase in expression compared with the genotype showing the lowest expression level. Bars represent the average ( \pm standard error) of two replicates. Letters in A through $\mathrm{D}$ indicate values that are significantly different $(\mathrm{P}$ $\leq 0.05$, analysis of variance with Bonferroni post hoc test). kinase (WAK) families as well as the recently described FEI1 and FEI 2 proteins may also serve as cell-wall sensors controlling cell growth and plant responses to pathogen-induced cellwall alterations (Hématy and Höfte 2008; Xu et al. 2008)

To identify new elements of ER-mediated immunity, a genetic screen was conducted in a mutagenized population of the highly susceptible $e r-1$ mutant to find suppressors of erecta susceptibility (ser) to the necrotrophic fungus $P$. cucumerina. Two mutants, serl and ser2, were identified that restored the er-1 susceptibility levels to those found in wild-type plants but failed to restore the er-associated development phenotypes to wild-type morphology. A comparative analysis of the cell-wall structure and composition and defense responses in these genotypes reveal that composition of the host cell wall may be a determinant of fungal infection success. The results presented here also suggest that ER plays a role in regulating cell wallmediated resistance to pathogens that is distinct from its role in plant development.

\section{RESULTS}

Isolation and characterization of ser mutants.

A suppressor screen was conducted to identify new elements of ER-mediated innate immunity. We inoculated about 10,000 M2 seedlings of the Landsberg er-1 (Ler) mutant with a spore suspension of $P$. cucumerina, and two recessive ser mutants, serl and ser2, were identified that, upon fungal inoculation, exhibited a reduction of fungus multiplication in planta, as demonstrated by quantification of $P$. cucumerina DNA by quantitative reverse transcriptase polymerase chain reaction (qRT-PCR) (Fig. 1A). The fungus multiplication in the ser plants was comparable to that of the wild-type plants (Landsberg, La-0) and lower than that observed in the highly susceptible $e r-1$ parental plants and the SA-compromised NahG line (Fig. 1A). The macroscopic disease ratings of ser 1 er- 1 and ser2 er-1 mutants at latter timepoints of infection (e.g., 14 days postinoculation [dpi]) correlated with the fungal biomass determined at the initial stages of infection (Fig. 1B).

Mapping was used to place $S E R I$ on chromosome 2 between markers T1D16A and F12K2A, a 500-kb interval encompassing ERECTA, and SER 2 on chromosome 5 between the markers nga151 and nga76 (data not shown). Genetic linkage analysis confirmed that SERI and $E R$ were tightly linked $\left(\chi^{2}=456, P=\right.$ 0.01 . The $E R$ coding region was sequenced in both $e r-1$ and serl er-1 plants, but no differences were found (data not shown). Thus, the serl mutation was not an intragenic mutation in $e r-1$. Also, the expression of $E R$ gene was quantified by qRT-PCR in the er-1, serl er-1, and ser 2 er- 1 plants, but no differences were found (data not shown). The $P$. cucumerina multiplication in the ser 2 single mutant was quantified by qRT-PCR at 3 dpi and was found to be slightly reduced compared with that of wild-type plants and the ser2 er- 1 double mutant (Supplementary Fig. 1).

To determine the specificity of the disease resistance of the ser 1 er- 1 and ser 2 er- 1 mutants, we infected the double mutants with a broad range of pathogens, including fungi, bacteria, and oomycetes. The ser 1 er- 1 and ser 2 er- 1 mutants were as susceptible as the parental er- 1 plants to most pathogens tested, with the exception of the biotrophic fungus Golovinomyces cichoracearum, which showed a slight reduction of growth on the serl er-1 mutant compared with the parental er-1 plants (Table 1; Supplementary Fig. 2). Interestingly, although ER is required for resistance to the soilborne bacterium $R$. solanacearum in Arabidopsis (Godiard et al. 2003), the disease symptoms caused by this pathogen on the ser 1 er- 1 and ser 2 er-1 mutants was similar to those observed in er-1 plants (Table 1). 
Genetic evidence indicates that the ET, JA, and SA signaling pathways are required for resistance to P. cucumerina in Arabidopsis and that the hyperactivation of any of these pathways is sufficient to increase plant resistance to this fungus (BerrocalLobo et al. 2002). We studied the activation status of these defense pathways in ser er-1 plants by testing the expression of marker genes of these signaling pathways. The expression of the SA-responsive gene PRI or the ET and JA-associated gene $P D F 1.2 a$ was not constitutively upregulated in uninfected serl er-1 and ser 2 er- 1 plants (Fig. 1C and D). Upon inoculation with $P$. cucumerina, the steady-state levels of these genes were lower in the ser er- 1 mutants than in the er- 1 plants (Fig. $1 \mathrm{C}$ and D). As described previously, in the NahG line blocked in SA-signaling (Berrocal-Lobo et al. 2002), the pathogeninduced expression of $P R I$ and $P D F 1.2 a$ was, respectively, lower and higher than in er-1 plants (Fig. 1C and D). These results suggest that the resistance mechanism in serl er-1 and ser 2 er- 1 plants to $P$. cucumerina may not be dependent on the constitutive activation of either the SA or JA and ET pathways.

\section{The serl and ser 2 mutants fail}

to suppress the $e r$-associated developmental phenotypes.

The different er mutant alleles display developmental alterations such as round leaves with short petioles, compact flower buds, and blunt, short, wide siliques as compared with wildtype plants (Lease et al. 2001; Torii et al. 1996). To determine whether the ser mutations suppressed these er-associated developmental alterations, we compared the flower buds as well as the pedicel and silique lengths of ser er-1 mutants with those of er-1 plants. As shown in Figure 2, the ser mutations were unable to restore the $e r$-1-associated developmental features to their wild-type morphology. By contrast, in the ser er1 plants, the flower buds were more compact and pedicels and siliques were even shorter than in $e r-1$ plants (Fig. 2A and C). Also, flowering time in the ser 2 er-1 plants was delayed about 3 weeks relative to $e r-1$ plants (data not shown). These data indicate that the SER1 and SER2 genes affected in a distinct manner the disease resistance mechanisms and the developmental processes regulated by ER.

\section{er-1 displays changes in its cell walls that are partially reversed in the ser er-1 double mutants.}

A role for the cell wall in Arabidopsis immunity has been proposed based on the identification of cell-wall mutants that show altered resistance to pathogens (Ellis and Turner 2001; Hernandez-Blanco et al. 2007; Vogel et al. 2002, 2004; Vorwerk et al. 2004). Moreover, some RLK, such as THE1, FEI1/FEI2, and some WAK members, have been suggested to regulate cellwall structure or integrity (Hématy and Hofte 2008; Hématy et al. 2007; Xu et al. 2008). Based on these observations and the enhanced susceptibility to different pathogens of er mutants (Llorente et al. 2005), we decided to explore whether ER function might impact the plant cell-wall structure. The walls from er- 1 and wild-type leaves were subjected to Fourier transform infra red (FTIR) spectroscopy to obtain qualitative spectratypes (i.e., cell-wall phenotype). The comparison of averaged FTIR spectra $(n=15)$ between samples from er- 1 and wildtype plants showed strong differences between the two genotypes (Fig. 3A). Much of the sample variation (96\%) was explained by principal component 1 (PC1) (Fig. 3B). Absorbances at $948 \mathrm{~cm}^{-1}, 1,066 \mathrm{~cm}^{-1}, 1,186 \mathrm{~cm}^{-1}$, common in the fingerprint for several cell-wall polysaccharides (Kauráková et al. 2000), and $1,402 \mathrm{~cm}^{-1}, 1,590 \mathrm{~cm}^{-1}$, and $1,708 \mathrm{~cm}^{-1}$ seemed to differ between er-1 and wild-type plants (Fig. 3C). In addition, FTIR spectra of a different mutant allele, er-115, in a distinct genetic background (Col-0) showed significant differences in the cell wall when compared with that of wild-type Col-0 (Supplementary Fig. 3). The pattern of the PC1 spectrum obtained (that explains $99 \%$ of the total variability) is similar to PC1 obtained from er-1/WT (Landsberg background), suggesting that $\mathrm{er}$ mutation produces similar changes in the cell wall in both genotypes.

To obtain a more quantitative analysis of the cell-wall changes in er-1, we compared the noncellulosic neutral monosaccharide composition as well as the cellulose and uronic acid
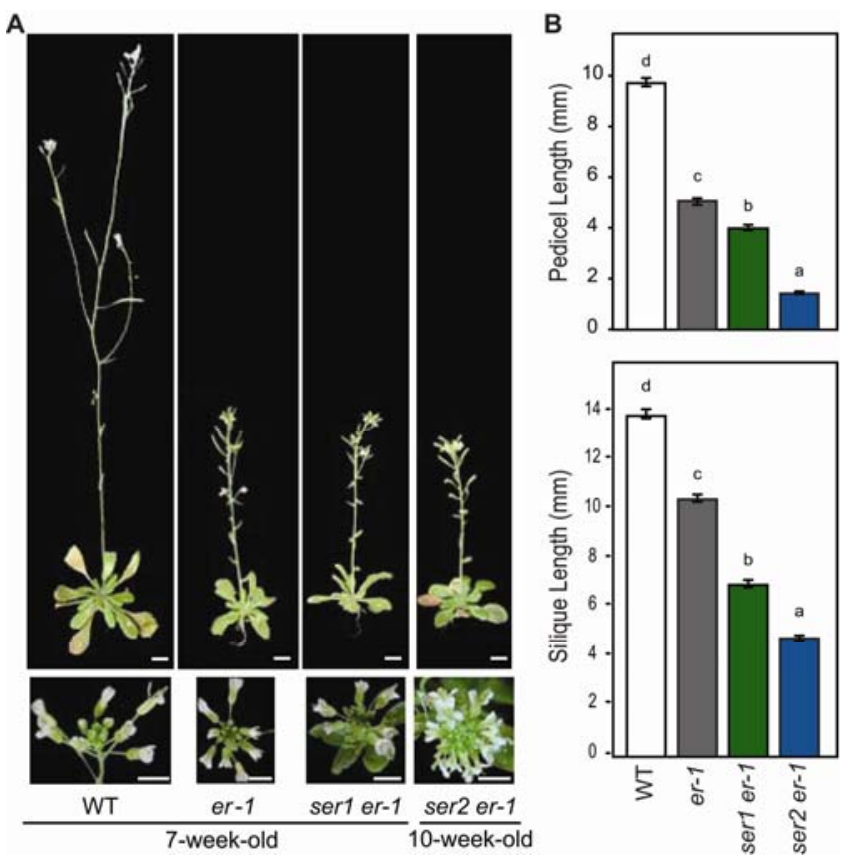

Fig. 2. Morphometric analysis of ser mutants. A, Developmental phenotype of 7-week-old wild-type, er-1, and ser 1 er-1 plants and of 10-weekold ser 2 er-1 plants. View of inflorescence of the four genotypes at bolting. Scale bar represents $1 \mathrm{~cm}$ in adult plants and $2.5 \mathrm{~mm}$ for inflorescences. B, Effect of ser mutations on the pedicel and silique lengths ( $\mathrm{mm})$. Average pedicel and silique lengths of plants $(n=10)$ from the indicated genotypes were measured as described previously (Torii et al. 1996). Letters indicate values that are significantly different from one another $(P \leq 0.01$, analysis of variance with Bonferroni post hoc test).

Table 1. Response of wild-type (WT; La-0), er-1, and ser er-1 plants to various pathogens ${ }^{\text {a }}$

\begin{tabular}{|c|c|c|c|c|c|}
\hline Pathogen & WT & er-1 & ser1 er-1 & ser2 er-1 & irx $1-1$ er-1 \\
\hline Golovinomyces cichoracearum USC1 & $\mathrm{S}$ & $\mathrm{S}$ & WR & $\mathrm{S}$ & WR \\
\hline Hyaloperonospora arabidopsis Noco 2 & $\mathrm{~S}$ & $\mathrm{~S}$ & S & $\mathrm{S}$ & S \\
\hline H. arabidopsis Cala2 & $\mathrm{R}$ & $\mathrm{R}$ & $\mathrm{R}$ & $\mathrm{R}$ & $\mathrm{R}$ \\
\hline H. arabidopsis Emwa1 & $\mathrm{R}$ & $\mathrm{R}$ & $\mathrm{R}$ & $\mathrm{R}$ & $\mathrm{R}$ \\
\hline Botrytis cinerea & $\mathrm{S}$ & $\mathrm{S}$ & $\mathrm{S}$ & $\mathrm{S}$ & WR \\
\hline Fusarium oxysporum f. sp. conglutinans & $\mathrm{S}$ & $\mathrm{S}$ & $\mathrm{S}$ & $\mathrm{S}$ & WR \\
\hline Ralstonia solanacearum GMI1000 & $\mathrm{R}$ & $\mathrm{S}$ & $\mathrm{S}$ & $\mathrm{S}$ & $\mathrm{R}$ \\
\hline Pseudomonas syringae pv. tomato DC 3000 & $\mathrm{~S}$ & $\mathrm{~S}$ & $\mathrm{~S}$ & $\mathrm{~S}$ & S \\
\hline P. syringae pv. tomato DC3000 AvrRPM1 & HR & HR & HR & HR & HR \\
\hline
\end{tabular}

${ }^{\text {a }} \mathrm{HR}=$ hypersensitive response, $\mathrm{R}=$ resistance, $\mathrm{S}=$ susceptible, and $\mathrm{WR}=$ weak resistance. The cell-wall mutant irx 1 - 1 er -1 was included for comparison. 
contents of the leaves from wild-type and er-1 plants (Blakeney et al. 1983; Reiter et al. 1993). The amounts of rhamnose, fucose, and xylose in er-1 samples were less than those found in wild-type cell walls (Fig. 4A). In the er-l cell walls, the uronic acids and cellulose contents were much greater than in wild-type cell walls (Fig. 4B). Taken together, these analyses of cell-wall composition highlight the impact of ER function on cell-wall composition and structure.

We next analyzed the cell wall of the ser er- 1 double mutants to determine whether ser mutations suppressed some of the er-1-associated cell-wall changes. PC analysis of the FTIR spectra $(n=15)$ of leaves from the different genotypes showed that ser mutations strongly reverted the er-1 cell-wall spectratype and also introduced some changes that make ser spectratypes different from that of wild type (Fig. 3D through F). PC1 explained almost $97 \%$ of the total variability in the data set (Fig. 3E). The absorbance features, which differed among the spectratypes of the four genotypes tested (PC1) (Fig. 3E and F), are shared by several cell-wall polysaccharides (Kauráková et al. 2000). This observation and the complexity of the PC spectra suggest that the cell-wall differences among er-1, serl er- 1 , and ser-2 er- 1 cannot be assigned to a defect in a single cell-wall polymer.

We also analyzed the amounts of noncellulosic neutral sugars and the cellulose and uronic acid content of the leaves of the ser er- 1 mutants. The ser 2 er- 1 cell walls showed higher levels of all six neutral sugars than did $e r-1$ cell walls (Fig. 4A). Except for xylose and arabinose, the amounts of these monosaccharides in serl er-l samples were similar to those found in the wild-type plants (Fig. 4A). In line with these results, we found that the total noncellulosic neutral sugar content in the cell walls of serl er-1 were restored to the wild-type levels, whereas in ser 2 er-1, the content was increased about $30 \%$ (wt/wt) relative to wild-type cell walls (Fig. 4A). Also, ser-1 er-1 and ser-2 er-1 plants showed lower levels of uronic acids than $e r-1$ and their cellulose content was slightly reduced compared with that of $e r-1$ plants (Fig. 4B).

To further characterize ser er-1-associated cell-wall modifications, we used immunodetection of cell-wall carbohydrate epitopes present in different polysaccharides. Though this type of qualitative analysis may be affected by differential accessibility of the antibodies to specific epitopes due to structural modifications of cell-wall polysaccharides, inmunodetection may allow the determination of a differential pattern distribution of carbohydrate epitopes in the cell walls of the mutants and wild-type plants (Fig. 4A and B). Immunodetection showed that the pattern of $(1 \rightarrow 4)-\beta$-D-galactan and $(1 \rightarrow 5)-\alpha$ L-arabinan epitopes was relatively similar in ser 2 er- 1 , serl er1 , and $e r-1$ leaves (Fig. 4C). The higher levels of neutral sugars together with the immunolabeling patterns found in the ser er-1 mutants, especially in ser2 er- 1 , suggests that rhamnogalacturonan-I (RG-I) accumulates to higher levels in the ser2 erl mutant and to modestly higher levels in the serl er- $1 \mathrm{mu}-$ tant, compared with er-1 plants. In addition, the pattern of a xylogalacturonan epitope, which is found in xylem vessels (Willats et al. 2004), was found to be slightly different in serl er- 1 and ser 2 er- 1 than in wild-type and $e r-1$ vascular bundles (Fig. 4C). Even though differences in fucose levels were observed between er 1 and the ser er- 1 mutants (Fig. 4A), no differences among wild-type plants, er-1, and the ser er-1 mutants were detected for the terminal nonreducing $(1 \rightarrow 2)$-linked $\alpha$-L-Fuc $p$ units (data not shown) usually present on the xyloglucan backbones and in RG-I polymers (Puhlmann et al.
A

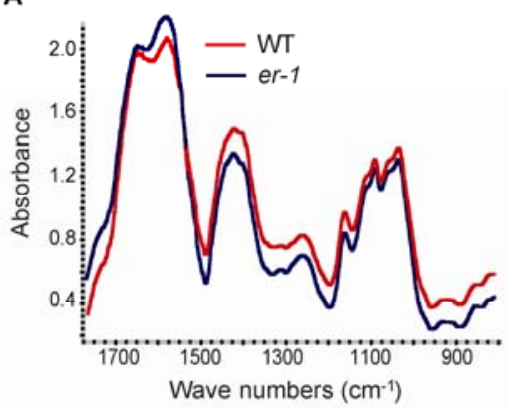

B

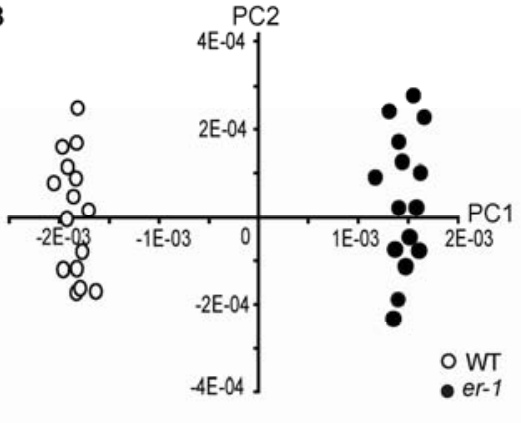

E

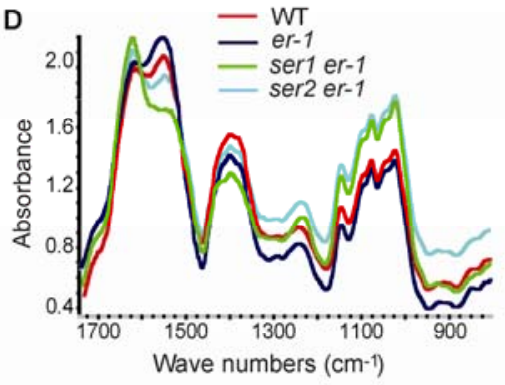

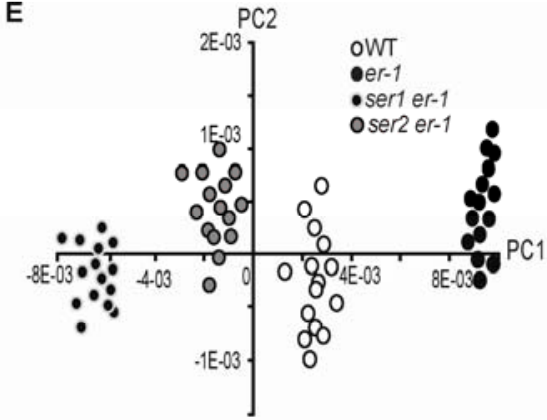

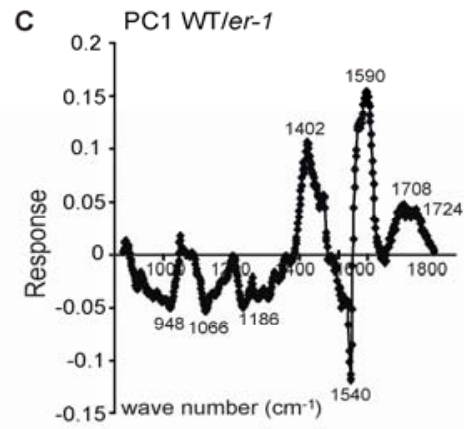

$\mathbf{F}$

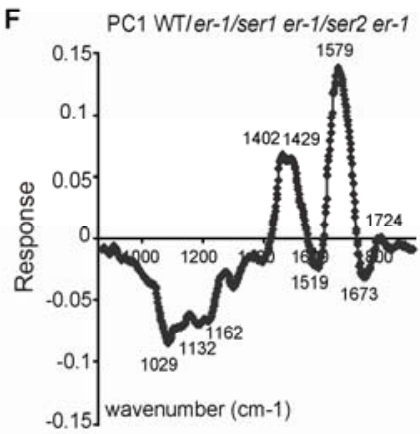

Fig. 3. Fourier transform infra red (FTIR) analysis of wild-type and mutant plant cell walls. A, FTIR averaged spectra $(n=15)$ from 3-week-old rosettes of wild-type plants (WT, red line) and er-1 (blue line). B, Biplot showing the separation of WT (white open circles) and er-1 (closed circles) samples. C, First principal component (PC1) from the covariance-matrix separation of the full infrared data sets WT and er-1. D, FTIR averaged spectra $(n=15)$ from 3week-old rosettes of wild-type (red), er-1 (dark blue), serl er-1 (green), and ser 2 er-1 (light blue) cell walls. E, Biplot showing the separation of wild-type (white, open circles), er-1 (black, closed circles), serl er-1 (gray-black circles), and ser2 er-1 (black-gray circles) samples. F, PC1 of the full infrared data sets obtained for the four genotypes shows clear differences between the er-1, wild-type, serl er-1, and ser2 er-1 genotypes. In B, C, E, and F, mid-infrared spectra were analyzed by the covariance-matrix approach for PC analysis (Kemsley 1996). 
1994). To determine if the differences in the uronic acid levels occurred in the homogalacturonan (HG) cell-wall fraction, we used the antibody $2 \mathrm{~F} 4$, which labels $\mathrm{Ca}^{+2}$ crosslinked $\mathrm{HG}$ (Guillemin et al. 2005), but no differences were detected (data not shown).

All together, these analyses revealed that ser mutations restored some features of the er- 1 cell wall to that of wild-type plants but also introduces additional cell-wall changes, further suggesting a direct correlation between cell-wall composition and structure and plant resistance to the necrotroph $P$. сucumerina.

\section{Arabidopsis cell-wall composition}

is a resistance determinant.

Recent genetic studies have shown that variation in cell-wall composition can result in altered disease resistance outcomes with various pathogens (Ellis and Turner 2001; HernándezBlanco et al. 2007; Osorio et al. 2008; Vogel et al. 2002, 2004). However, a direct correlation between cell-wall composition and structure and pathogen resistance has not been demonstrated. As shown in Figure 5, a positive correlation $(r=0.9$; $P=0.026)$, explained by a logaritmic-X nonlinear model, was found between the $P$. cucumerina biomass and the uronic acids
A

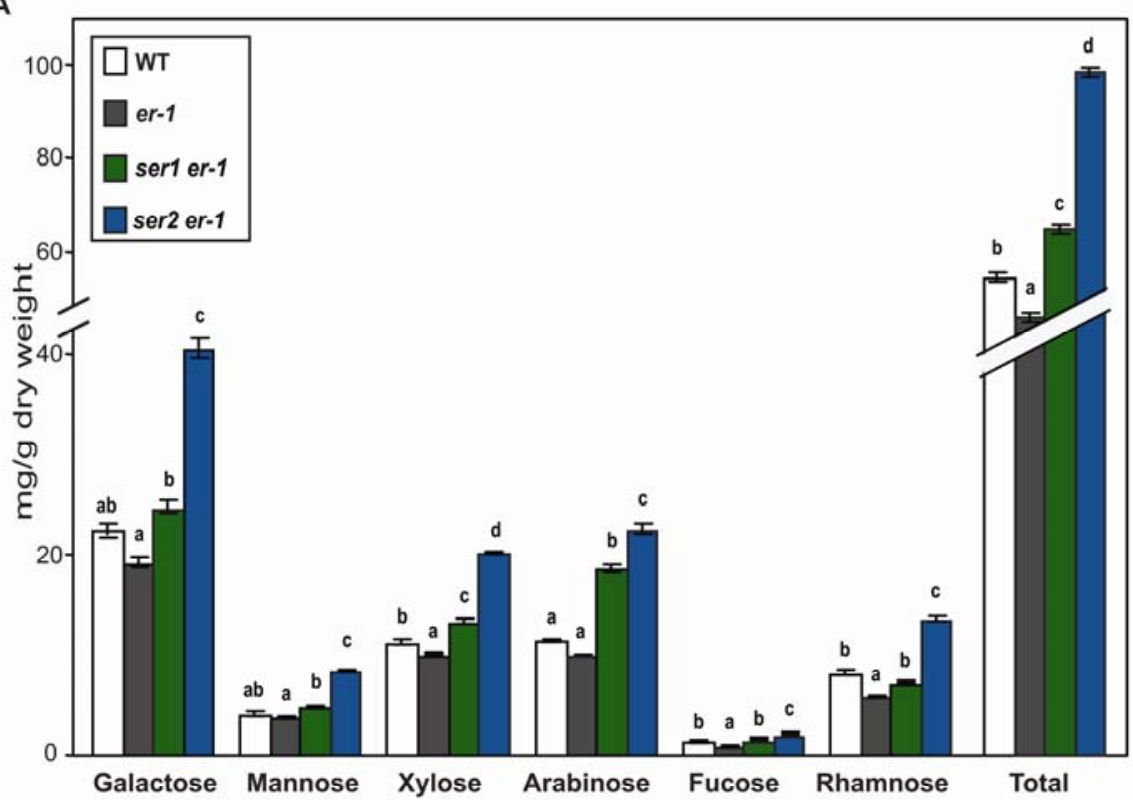

B

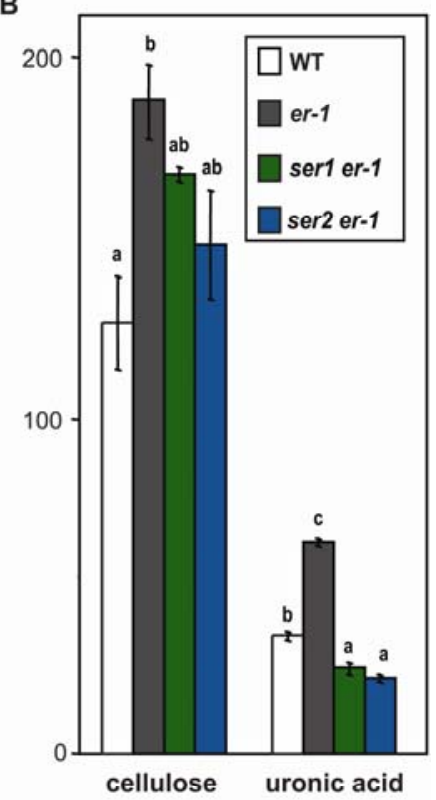

C

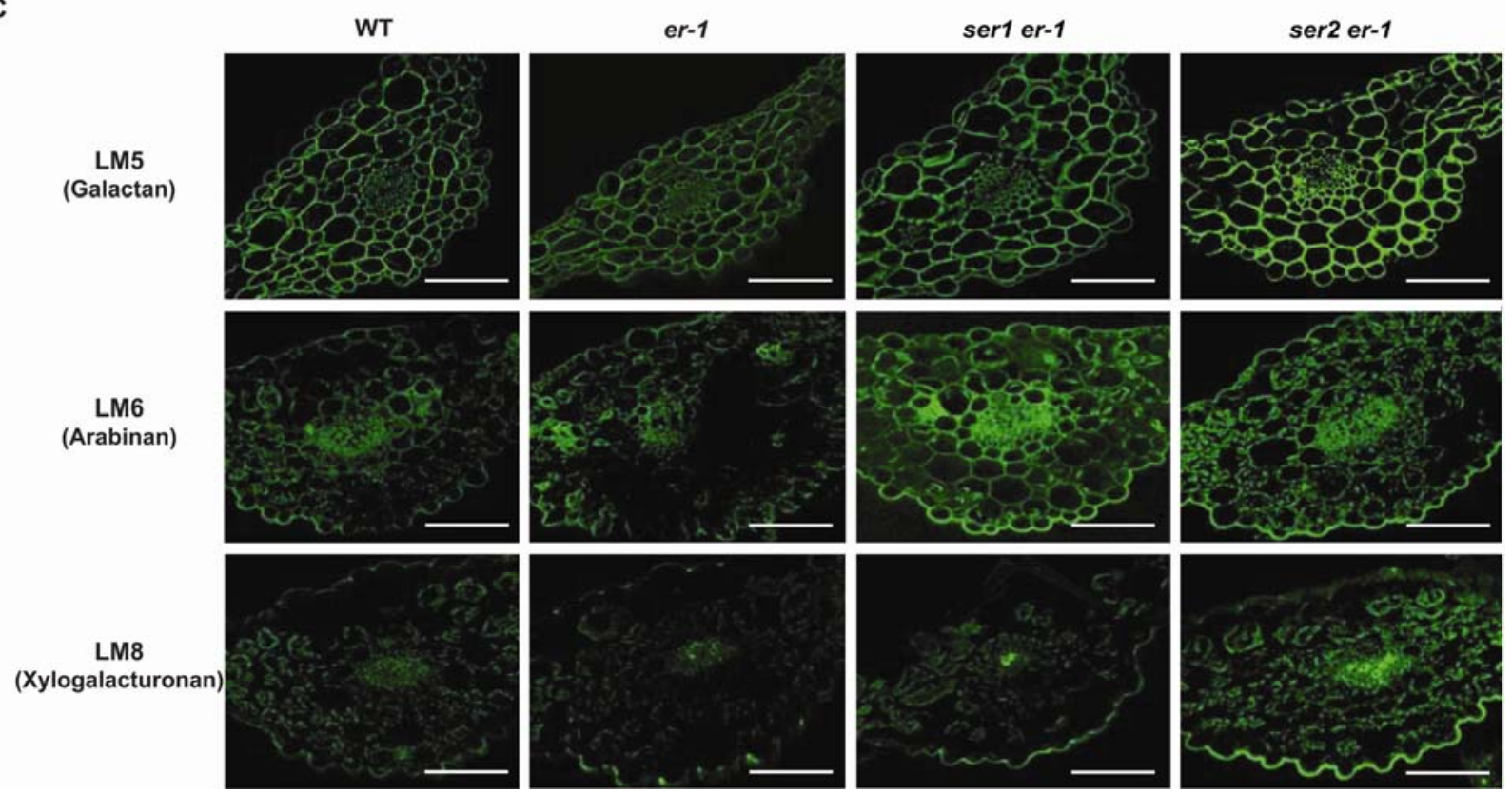

Fig. 4. Composition analysis of wild-type, er-1, and ser er-1 cell walls. A, Quantification of total and individual neutral sugars (milligrams per gram of dry weight) from the noncellulosic carbohydrate fraction and $\mathbf{B}$, of the cellulose and total uronic acids content (milligram per gram of dry weight) of the cell walls from wild-type (white bar), er-1 (gray bar), serl er-1 (green bar), and ser 2 er-1 (blue bar). Data represent average values ( \pm standard error) of three (A) or two (B) replicates. Statistical analysis of the data was performed using analysis of variance $(P \leq 0.05)$ and the Bonferroni post hoc test. C, Confocal images of leaf cross-sections showing the in situ localization of different pectin epitopes in the indicated genotypes. Specific monoclonal antibodies were used: LM-5, which detects (1->4)- $\beta$-D-galactan (Jones et al. 1997); LM-6, which detects (1->5)- $\alpha$-L-arabinan (Willat et al. 1998); and LM-8, which detects xylogalacturonan (Willats et al. 2004). Images are representative pictures from 15 different plants. In some cases, autofluorescence derived from waxes in the abaxial epidermis was detected. Scale bar represents $100 \mu \mathrm{m}$. 
content in the er-1, ser er-1, and wild-type cell walls. Based on this analysis, the modified cell-wall uronic acids content accounted for $94 \%$ of the variation in resistance to $P$. cucumerina of the genotypes tested. Similar analyses were performed with additional cell-wall parameters, such as cellulose or noncellulosic neutral sugars contents. No correlation was found between resistance to the fungus and cellulose content in the genotype tested $(r=0.4 ; P=0.6)$, whereas a weak, negative correlation ( $r=0.83$ and $P=0.17$ ) was identified for noncellulosic neutral sugars content (Supplementary Fig. 4).

We next asked whether the susceptibility to $P$. cucumerina of $e r$ alleles would be suppressed by additional cell-wall mutations, such as the irxl mutant (Hernández-Blanco et al. 2007). Susceptibility of the er-1 mutant was restored to almost wildtype (La-0) levels in the er-l irxl double mutant (Fig. 6A). Similar results were obtained in a different genetic background (Col-0) by comparing the susceptibility to $P$. cucumerina of wild-type plants, the er-115 mutant, and the irx $1-6$ er-115 double mutant (Fig. 6A). In contrast to the irxl-1 er-1 double mutant, the ser er-1 mutants were not more resistant to the soilborne bacteria $R$. solanacearum (Table 1) (Hernández-Blanco et al. 2007). These results suggest that the enhanced susceptibility to necrotrophic pathogens of er mutants may be related with specific alterations of their cell wall.

The ir $x$-mediated resistance has been demonstrated to partially depend on the constitutive activation of ABA signaling, which has emerged as a key regulatory pathway for plant resistance (Asselbergh et al. 2008; Mauch-Mani and Mauch 2005), and on the upregulation of the indole glucosinolate-derived secondary metabolite pathway (e.g., $C Y P 79 B 2$ and $C Y P 79 B 3$ genes) (Hernández-Blanco et al. 2007), which was recently found to play a role in Arabidopsis resistance to several fungi, including $P$. cucumerina (Bednarek et al. 2009). To determine whether ser-mediated resistance was distinct from that activated by irxl mutation, the expression levels of $C Y P 79 B 2$, $C Y P 79 B 3$, and the ABA-responsive genes (e.g., $A B I 1, A B I 2$, NCED3, and LTP3), which are constitutively upregulated in the irxl mutant, were determined by qRT-PCR in serl er-1, ser 2 er- 1 double mutants, and er-1 plants. No differences were found, except for the upregulation of the $C Y P 79 B 2$ and $C Y P 79 B 3$ genes in serl er-1 plants compared with the parental line $e r-1$ (Fig. 6B). These data indicate that, in contrast to the irxl mutant, the resistance to $P$. cucumerina of ser er-1 mutants cannot be explained by constitutive activation of ABA signaling and that the reduced susceptibility of serl er-1 plants to $P$. cucumerina and G. cichoracearum (Table 1) may depend,

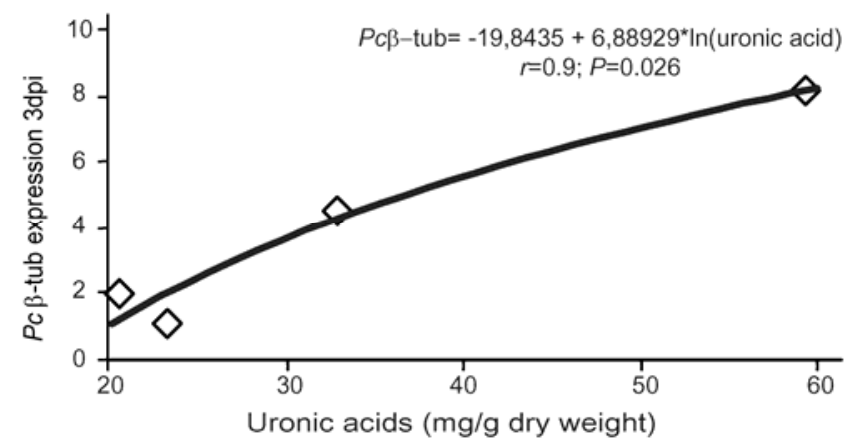

Fig. 5. Correlation between leaf uronic acids content and susceptibility to Plectosphaerella cucumerina. Uronic acids content was measured as milligrams per gram of dry weight. The susceptibility to $P$. cucumerina was estimated from the amount of fungal DNA amplified by quantitative reverse transcriptase polymerase chain reaction from infected plant samples. Data are based on uronic acids content and $P c$ - $\beta$ tub expression mean values at 3 days postinoculation from five and two replicates per genotype, respectively. at least in part, on the elevated expression of genes of the indole glucosinolate-derived metabolites. As this pathway leads to the biosynthesis of both indole glucosinolate and camalexin, and this last metabolite has been shown to be important for plant resistance to different pathogens, including necrotrophic fungi (Ferrari et al. 2007). We determined the expression of the $P A D 3$ gene, which encodes a key enzyme of camalexin biosynthesis in the ser mutants. No differences were found in the ser2 er-1 mutant, whereas PAD3 expression was slightly downregulated in the ser 1 er- 1 mutant, respectively to er -1 and wild-type plants (Supplementary Fig. 5).

\section{Callose deposition after $P$. cucumerina infection is restored to wild-type levels in ser er-1 mutants.}

The deposition of callose, a high-molecular weight $\beta-1,3-$ glucan, is a widely recognized early response of host plant cells to microbial attack, treatment with elicitors or MAMPs, or breaks in the cell wall caused by wounding (Gomez-Gomez et al. 1999; Nishimura et al. 2003; Wei et al. 1998). The er mutants do not accumulate callose specifically upon $P$. сuсumerina infection but do deposit callose following inoculation with the oomycete Hyaloperonospora arabidopsis or after treatment with flg22 (Gomez-Gomez et al. 1999; Llorente et al. 2005). This selective effect on $P$. cucumerina-induced callose accumulation in $e r-1$ mutants suggests that ER potentially sensitizes the plant callose response to this necrotophic fungus. We decided to explore whether ser er-1 double mutants deposited callose at sites of $P$. cucumerina infection. As shown in Figure 7, callose deposition following inoculation with $P$. $\mathrm{cu}$ cumerina was substantially higher in ser 2 er- 1 than in $e r-1$ and wild-type plants and was more similar to wild-type in serl er1 plants. In contrast, the deposition of callose upon wounding was found to be similar in all genotypes (Fig. 7), showing that the lack of callose accumulation in er- 1 upon $P$. cucumerina infections was not due to a defect in callose synthesis or deposition per se. The expression of the PMR4 gene, encoding a component of the pathogen- and wound-inducible callose synthase (Nishimura et al. 2003), was analyzed in the different genotypes under study; however, no difference in PMR4 expression upon infection was found (data not shown). Thus, an inverse relationship exists between the disease ratings for $P$. cucumerina infections and callose deposition in the genotypes under study, suggesting that either ER has multiple independent pleiotropic effects on plants or that these features may be mechanistically linked through ER.

\section{DISCUSSION}

ER was initially identified as a LRR RLK that regulates development in several ways, including organ shape and floral architecture determination and stomatal patterning (Lease et al. 2001; Masle et al. 2005; Torii et al. 1996). More recently, ER has also emerged as a key regulator of basal resistance, as Arabidopsis er mutants (e.g., er-1) display an enhanced susceptibility to different types of pathogens, including the bacterium $R$. solanacearum, the fungus $P$. cucumerina and the oomycete Phythium irregulare (Adie et al. 2007; Godiard et al. 2003; Llorente et al. 2005). It was unknown whether the molecular components of one or more ER-associated signaling pathways regulating immunity and development were identical or distinct. Here, we show that at least some genetic components (e.g., SER 1 and SER2) of the ER signaling pathway regulate these biological processes in a opposite ways, as ser er-1 double mutants suppressed the disease susceptibility of er-1 plants (Fig. 1), while they enhanced the er-associated developmental alterations (Fig. 2). Interestingly, the enhanced susceptibility of er- 1 to $R$. solanacearum was not modified by the ser muta- 
tions (Table 1), suggesting that specific defensive mechanisms effective against only a subset of pathogens might operate downstream of ER. The genetic mapping of the SERI and $S E R 2$ genes indicate that ser phenotypes were not due to either
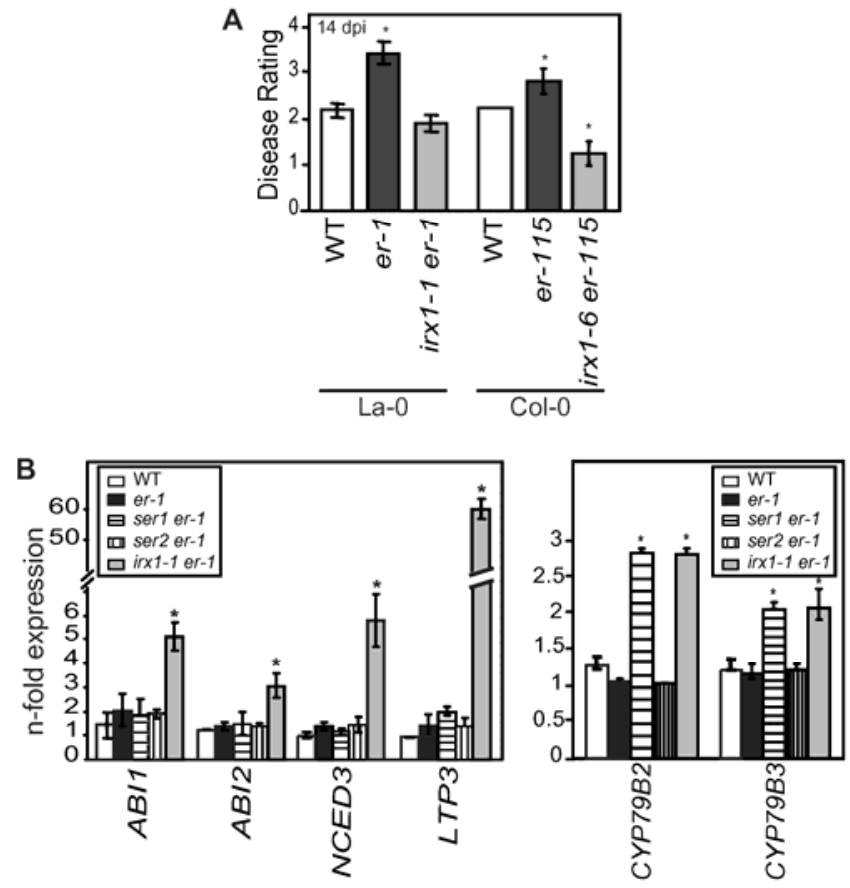

Fig. 6. The susceptibility to Plectosphaerella cucumerina of er-1 plants is restored to wild-type levels by the secondary cell-wall irxl mutant. A, Average disease rating (DR \pm standard deviation) of wild-type plants (WT, La-0 or Col-0, white bars), er-1, and er-115 mutants (dark gray bars), and the irx 1-1 er-1 and irx 1-6 er-115 double mutants (light gray bars) 14 days postinoculation with $P$. cucumerina at the rate of $4 \times 10^{6}$ spores $/ \mathrm{ml}$. DR varies between 0 (no symptoms) and 5 (dead plant). Data are from one of four independent experiments that all gave similar results. Asterisks indicate values that are significantly different from wild-type plants $(P \leq 0.05$, analysis of variance [ANOVA] Bonferroni test). B, Analysis of the expression in ser mutants of various genes that are constitutively upregulated in irxl plants (HernándezBlanco et al. 2007). The steady-state levels of the abscisic acid-responsive genes (i.e., $A B I 1, A B I 2, N C D E 3$, and $L T P 3$ ) and the $C Y P 79 B 2$ and $C Y P 79 B 3$ genes were determined by quantitative reverse transcriptase polymerase chain reaction. RNA samples from noninoculated leaves of 3-week-old La-0 (WT; white bars), er-1 (black bars), serl er-1 (horizontal stripped bars), ser 2 er-1 (vertically stripped bars), and irx $1-1$ er-1 (gray bars) plants were used for the analyses. Values were normalized relative to ubiquitin and presented as the fold-increase in expression compared with the genotype showing the lowest expression levels. Data are the average ( \pm standard error) of three replicates. Asterisks indicate values significantly different $(P \leq 0.05$, ANOVA Bonferroni test) from those of WT plants. an intragenic mutation in the $E R$ gene, a mutation in any of the already described $E R$ genetic interactors (e.g., ERL1, ERL2, and TMM [Shpak et al. 2003, 2004, 2005]), nor a constitutive activation of the YUCCA5 gene, which restored the er-associated developmental alterations to wild-type morphology (Woodward et al. 2005). Thus, SER1 and SER2 are novel genetic components that deserve additional investigation.

Resistance to necrotrophic fungi such as $P$. cucumerina depends on the coordinate regulation of multiple signaling pathways, including the SA, ET, JA, and ABA pathways (BerrocalLobo et al. 2002; Hernández-Blanco et al. 2007; Llorente et al. 2005). Expression analysis of defense marker genes suggested that none of these pathways are constitutively activated in the serl er-1 and ser 2 er-1 mutants (Figs. $1 \mathrm{~B}$ and $\mathrm{C}$ and $6 \mathrm{~B}$ ). However, as it has been reported in the irxl-1 er-1 mutant (Hernández-Blanco et al. 2007), the CYP79B2 and CYP79B3 genes were constitutively expressed in serl er-1 (Fig. 6C), which may lead to enhanced accumulation of indole glucosinolate-derived metabolites and enhanced resistance to some pathogens, including G. cichoracearum (Table 1). In contrast, the $P A D 3$ gene, required for plant resistance to several pathogens including the necrotroph B. cinerea (Ferrari et al. 2007), was not constitutively upregulated in ser mutants, indicating that ser-mediated resistance may not be dependent on an enhanced accumulation of camalexin in the ser er-1 mutants.

The cell wall has emerged as a dynamic and responsive structure that regulates plant responses to external stimuli or stresses (Humphrey et al. 2007). Recent genetic data show that specific changes in cell-wall composition can result in altered immune responses to different type of pathogens, including the necrotroph $P$. cucumerina and the biotroph $G$. cichoracearum (Ellis and Turner 2001; Hernández-Blanco et al. 2007; Vogel et al. 2002, 2004). Here, we show that impairment of ER in Arabidopsis resulted in alterations of cell-wall composition that may lead to changes in structure (Figs. 3 and 4). The content of noncellulosic neutral sugars, in particular those of the pectin fraction, possibly associated with RG-I structures, were significantly lower in the cell wall of er-1 than in that of wildtype plants (Fig. 4). However, the uronic acid content was clearly higher in er-1, possibly deriving from the partially methyl-esterified HG structures, since no differences in the nonesterified $\mathrm{HG}$ crosslinked by $\mathrm{Ca}^{+2}$ bridges (recognized by the 2F4 antibody) were detected. However, additional analyses will be required to corroborate this conclusion, as inmunodetection results are qualitative. In addition, cellulose levels were also significantly increased in er-1 compared with those in wild-type plants (Fig. 4). Notably, cellulose levels have been shown to be reduced in the irx CESA mutants, which showed an enhanced resistance to several pathogens (Hernández-
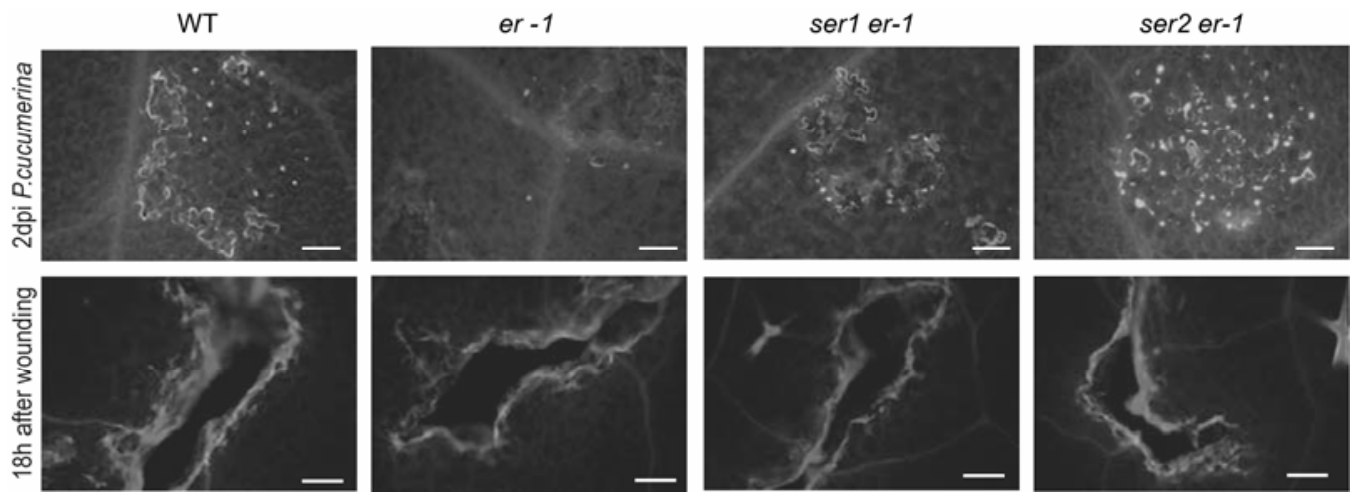

Fig. 7. Callose deposition in leaves of wild-type, er-1, and ser er-1 plants upon Plectosphaerella cucumerina infection and wounding. Callose staining in plants 2 days postinoculation with $P$. cucumerina or $18 \mathrm{~h}$ after leaves were injured with a syringe. At least three leaves per plant and 10 plants per genotype were tested. Scale bar represents $500 \mu \mathrm{m}$. 
Blanco et al. 2007). It is unclear whether all these er-1-associated cell-wall changes are a direct consequence of the inactivation of ER function or an indirect effect.

Interestingly, the serl and ser2 mutations partially restored to wild-type levels some of these changes in $\mathrm{er}-1$ cell-wall composition and introduced some additional cell-wall changes, suggesting a direct linkage between cell-wall composition and resistance to $P$. cucumerina. The positive correlation found between uronic acids content of the cell walls from er-1, serl er1 , ser 2 er-1, and wild-type plants and their levels of resistance to $P$. cucumerina highlights the importance in disease resistance against this pathogen of this metric of cell-wall composition over other cell-wall changes and suggests that cell-wall composition and, consequently, cell-wall structure is a determinant of the success of fungal colonization (Fig. 5).

In yeast, there is a mechanism controlling cell-wall integrity that is regulated by the WSC genes (for cell-wall integrity and stress response), which encode integral membrane proteins acting as surface sensors responding to environmental stress (Philip and Levin 2001). In plants, a similar sensing system to that of yeasts has been proposed, and several members of the CrRLK1L and WAK families have been suggested to function as cell-wall integrity sensors (Hématy and Höfte 2008). For example, the the 1 mutant attenuates the development-associated phenotypes of the primary cell-wall mutants prc and elil (Hématy et al. 2007). Interestingly, some WAK RLK have been found to bind covalently cell wall-derived pectins (Humphrey et al. 2007), and THE1 has been suggested to detect cell-wall components that accumulate upon perturbation of cellulose synthesis (Hématy and Höfte 2008). It has been demonstrated that some Arabidopsis wak mutants show disease resistance alterations (Diener and Ausubel 2005; Wagner and Kohorn 2001) and that THE1 regulates the expression of some defenserelated genes (Hématy et al. 2007). Despite all these data, a direct link between cell-wall alterations and disease resistance has not been established for these mutants.

Although other interpretations are possible, we speculate that ER may be acting as a cell-wall integrity sensor responding to plant cell-wall fragments released by pathogens. The nature of such plant cell wall-derived signals remains unknown. Oligogalacturonides, which have been demonstrated to activate plant innate immunity (Denoux et al. 2008; Osorio et al. 2008), may be potential candidates. In this model, the recognition by ER of either a cell wall-derived ligand or cell-wall perturbations would lead to the activation of immune responses such as callose deposition, as it has been described for other RLK after MAMP recognition (Gomez-Gomez et al. 1999). The data presented here and published previously (Hématy and Höfte 2008; $\mathrm{Xu}$ et al. 2008) suggest that some RLK may be involved in the detection of pathogen- or development-induced perturbations of cell-wall integrity. The identification of the corresponding ligands and downstream effectors of these RLK cell-wall sensors is a future challenge in the plant field.

\section{MATERIALS AND METHODS}

\section{Plant growth and pathogenicity assays.}

Arabidopsis plants were grown either in soil or in vitro (Hernández-Blanco et al. 2007). Spores from the fungi Plectosphaerella cucumerina, Botrytis cinerea, Fusarium oxysporum f. sp. conglutinans, Golovinomices cichoracearum UCSC1, and conidiospores from the oomycete Hyaloperonospora arabidopsis (isolates Noco2, Cala2, and Emwa2) were collected as reported (Hernández-Blanco et al. 2007). The bacteria Pseudomonas syringae pv. tomato DC3000 were grown on nutrient broth at $28^{\circ} \mathrm{C}$ as described previously (Berrocal-Lobo et al. 2002). The soilborne bacterium $R$. solanacearum
GMI1000 was grown at $28^{\circ} \mathrm{C}$ in B broth medium (Boucher et al. 1985).

Plant infections with fungi, bacteria, and oomycete were performed as described (Hernández-Blanco et al. 2007). After inoculation, disease progression was estimated, depending on the pathogen, as average disease rating, bacterial growth, or conidiospore formation (Hernández-Blanco et al. 2007). All the pathogenicity assays were repeated at least three times and a minimun of 20 plants per genotype were inoculated in each experiment. Since the data of all the disease-resistance experiments were homocedastic, differences in these parameters according to Arabidopsis genotype were analyzed by one-way analysis of variance (ANOVA) using plant genotype as factor. To determine whether values of analyzed traits were significantly different among classes within each factor the Bonferroni post hoc test was employed.

For callose detection, 3-week-old plants were wounded, mock-inoculated or challenged with a spore suspension $(4 \times$ $10^{6}$ spores $/ \mathrm{ml}$ ) of $P$. cucumerina, and callose staining was performed (Vogel and Somerville 2000).

\section{Isolation, mapping, and characterization} of $\operatorname{ser} 1$ and $\operatorname{ser} 2$ mutants.

For the identification of ser mutants, about 10,000 10-dayold plants of an ethyl methanesulfonate M2 mutagenized population of Arabidopsis er- 1 were sprayed with a concentration of $2 \times 10^{6}$ spores $/ \mathrm{ml}$ of $P$. cucumerina. SERI and SER2 genes were mapped using 300 and 20 selected mutant individuals from serl er- $1 \times$ Col- 0 and ser 2 er $-1 \times$ Col- 0 F2 populations, respectively. New markers within the SERI mapping interval on chromosome II were generated using the CEREON database of Col-0 and er-1 (Ler) polymorphisms. The ser 2 plants were obtained by crossing ser 2 er $-1 \times \mathrm{La}-0$, and selecting ser 2 F2 individuals lacking the $e r-1$ mutation. The derived oligonucleotide sequences used for mapping are showed in the Supplementary Table 1. For ER sequencing, RNA was extracted from 3-week-old plants and cDNA was synthesized using oligo(dT) as reported (Llorente et al. 2005). Oligonucleotides used for cDNA amplification and sequencing were 5'-TCTTC TTCATGGAGACTTGAAAGC-3'， 5'-GAGGAGGATTATGC GGTCGG-3', 5'-GGCCCAATTCCAGAAGAGCT-3', and 5'TATAGGAAGTCTAAGTGCCAGTCTG-3'. Determination of the pedicel and silique length of the genotypes analyzed was done as described by Torii and associates (1996). The first five fruits from ten 7-week-old (wild-type, er-1, and serl er-1) or 10-week-old plants (ser2 er-1) were measured.

\section{Cell-wall analyses.}

For FTIR, precleaned (by solvent extractions) dried leaves from at least 30 3-week-old individual plants per genotype were pooled and homogenized by ball milling. The powder was dried and mixed with potassium bromide and, then, pressed into 13-mm pellets. For each line, 15 FTIR spectra were collected on a Thermo Nicolet Nexus 470 spectrometer (ThermoElectric Corporation, Chicago) over a range of 4,000 to $400 \mathrm{~cm}^{-1}$. For each spectrum, 32 scans were co-added at a resolution of $4 \mathrm{~cm}^{-1}$ for Fourier transform processing and absorbance spectrum calculation, using OMNIC software (Thermo Nicolet, Madison, WI, U.S.A.). Using win-das software (Wiley, New York), spectra were baseline-corrected and were normalized and analyzed, using the PC analysis covariance matrix method (Kemsley 1996).

Cell-wall monosaccharides were assayed as alditol acetate derivatives (Stevenson and Furneaux 1991) by gas chromatography performed on an Agilent 6890N gas chromatograph (Wilmington, DE, U.S.A.), and the results obtained were validated with the method previously described by Gibeaut and 
Carpita 1991. Myo-Inositol (Sigma-Aldrich, St Louis) was added as an internal standard. Cellulose was determined on the fraction resistant to extraction with $2 \mathrm{M}$ trifluoracetic acid (TFA) $(n=4)$ by phenol-sulfuric assay using glucose equivalents as standard (Dubois et al. 1956). Uronic acids were quantified using the soluble 2M TFA fraction $(n=5)$ (FilisettiCozzi and Carpita 1991). The data were analyzed using oneway ANOVA with the Bonferroni post hoc test. The correlation between uronic acids and $P$. cucumerina biomass was tested using product-moment coefficient. All statistical analyses were performed using the statistical software package SPSS 13.0 (SPSS Inc., Chicago).

For carbohydrate epitope detection, intact leaves were sectioned by hand and were then fixed in $4 \%$ formaldehyde for 1 to $2 \mathrm{~h}$. Cross-sections were washed in phosphate-buffered saline (PBS) and were then extracted in $\mathrm{EtOH}$ and rehydrated in series of EtOH-PBS until $1 \times$ PBS. Sections were blocked in PBS containing $5 \%(\mathrm{wt} / \mathrm{vol})$ fat-free milk powder $(5 \%$ milk phosphated buffer solution [MPBS]) for $30 \mathrm{~min}$. Rat monoclonal antibodies specific for various carbohydrate epitopes were used: antibody LM-5, $(1 \rightarrow 4)-\beta$-D-galactan (Jones et al. 1997); LM-6, (1 $\rightarrow 5)-\alpha-L-a r a b i n a n$ (Willats et al. 1998); LM-8, xylogalacturonans (Willats et al. 2004); CCRC-M1, terminal nonreducing $(1 \rightarrow 2)$-linked $\alpha$-L-Fucp units (Puhlmann et al. 1994), and 2F4, $\mathrm{Ca}^{+2}$ crosslinked homogalacturonans (Liners et al. 1989). Sections were incubated with the primary antibody (dilution $1: 50$ to $1: 1,000$ ) in $5 \%$ MPBS 1 to $2 \mathrm{~h}$ at room temperature and were washed twice with PBS. To visualize the primary antibody binding, anti-rat immunoglobulin coupled with Alexa Fluor 488 (Molecular Probes, Eugene, OR, U.S.A.) $(1: 1,000)$ in $5 \%$ MPBS was added for $1 \mathrm{~h}$ at room temperature. After washing with PBS for 5 min (two times), the samples ( $n=$ 20 ) were observed in a laser scanning confocal microscope. As a control, primary antibodies were omitted during the labeling procedure. Confocal imaging was performed using an MRC 1024 laser scanning confocal head (Bio-Rad, Hercules, CA, U.S.A.) mounted on a Diaphot 200 inverted microscope (Nikon, Tokyo), a Zeiss 510 laser scanning confocal microscope. The samples were excited with two lasers $(\mathrm{Ar} / \mathrm{Kr}$ and $\mathrm{He} / \mathrm{Cd}$ ) at the following wavelengths: $568 \mathrm{~nm}$ for checking chlorophyll fluorescence and at $488 \mathrm{~nm}$ for detecting the secondary antibody coupled to Alexa fluor 488 dye. Three-dimensional reconstructions of image stacks $(n=5)$ were carried out using Image $\mathrm{J}$ version 1.34 software. All images were processed with Adobe Photoshop 7.0 (Adobe Systems, Mountain View, CA, U.S.A.) and were assembled with Illustrator (Adobe Systems, San Jose, CA, U.S.A.) software.

\section{Expression profiling.}

RNA extractions from $P$. cucumerina-infected or mockinoculated plants were done as described by Llorente and associates (2005). Real-time qRT-PCR analyses were done as previously reported (Hernández-Blanco et al. 2007). Ubiquitin (AT5G25760) expression was used to normalize the transcript level in each sample. Oligonucleotides used for cDNA amplification were designed with Primer Express (version 2.0; Applied Biosystems, Foster City, CA, U.S.A.): Ubiquitin (AT5G25760), 5'-AAAGGACCTTCGGAGACTCCTTACG-3' and 5'-GGTCAAGAATCGAACTTGAGGAGGTT-3'; PRI (AT2G14610), 5'-CGAAAGCTCAAGATAGCCCACA-3' and 5'-TTCTGCGTAGCTCCGAGCATAG-3'; PDF1.2a (AT5G44420) 5'-TTCTCTTTGCTGCTTTCGACG-3' and 5'GCATGCATTACTGTTTCCGCA-3'; CYP79B2 (AT4G39950), 5'-GCCGACCCACTTTGCTTTAAA-3' and 5'-GCACAACC TCTTTTCCCGGTA-3'; CYP79B3 (AT2G22330), 5'-ATGCTA GCGAGGCTTTTGCA-3' and 5'-CCAACACCAAAGGCTT CGAA-3'; ABI1, (AT4G26080): 5'-TGTTTTCCCGTCTCAC
ATCTTC-3' and 5'-CCGGTTTATGGTCAACGGAT-3'; $A B I 2$ $(A T 5 G 57050)$, 5'-TCAGTGCGGCGAGTAAAAGAA-3' and 5'-TCCG-TTTCCGAGCCAAATC-3'; LTP3 (AT5G59320), 5'GAAG-AGCATTTCTGGTCTCAAC-3' and 5'-GTTGCAGTT AGTGCTCATGGA-3'; NCDE3 (AT3G14440), 5'-ACATCT TTACGGCGATAACCG-3' and 5'-TTCCATGTCTTCTCGT CGTGA-3'; ERECTA (AT2G26330), 5'-GGCACTCCTATG CACCAAAAGA-3' and 5'-CAGCAGGTGGTTGTTCCGAT A-3'; PMR4 (AT4G03550), 5'-TCGTCCGCCGTATGTTC AAT-3' and 5'- AAGCACCATATGCTCACGCTG-3'; $P c \beta$ tubulin, 5'-CAAGTATGTTCCCCGAGCCGT-3' and 5'-GG TCCCTTCGGTCAGCTCTTC-3'; PAD3 (AT3G26830), 5'-CA ACAACTCCACTCTTGCTCCC-3' and 5'-CGACCCATCGC ATAAACGTT-3'.

\section{ACKNOWLEDGMENTS}

We thank F. García-Arenal and F. García-Olmedo for helpful discussions, G. López, for technical assistance, and M. R. Ponce and J. L. Micoll (GEFA Mapping Service, UMH, Spain) for SER2 mapping assistance. Work in the A. Molina laboratory was supported by Spanish Ministerio de Educación y Ciencia grants BIO2003-4424 and BIO2006-00488). C. Sánchez-Rodríguez and C. Hernández-Blanco were PhD Fellows from the MEC, and F. Llorente a Postdoc Fellow from the Comunidad Madrid (Spain). J. Estevez was supported by a grant from the U. S. Department of Energy to C. R. Somerville (Carnegie Institution of Science, Stanford, CA, USA). Work in the S. Somerville laboratory was supported in part by the U. S. Department of Energy, the National Science Foundation, and the Carnegie Institution of Science.

\section{LITERATURE CITED}

Adie, B. A., Perez-Perez, J., Perez-Perez, M. M., Godoy, M., SánchezSerrano, J. J., Schmelz, E. A., and Solano, R. 2007. ABA is an essential signal for plant resistance to pathogens affecting JA biosynthesis and the activation of defenses in Arabidopsis. Plant Cell 19:1665-1681.

Asselbergh, B., De Vleesschauwer. D., and Höfte M. 2008. Global switches and fine-tuning-ABA modulates plant pathogen defense. Mol Plant-Microbe Interact. 21:709-19.

Ausubel, F. M. 2005. Are innate immune signaling pathways in plants and animals conserved? Nat Immunol, 6:973-979.

Becraft, P. W. 2002. Receptor kinase signaling in plant development. Annu. Rev. Cell Dev Biol. 18:163-192.

Bednarek, P., Piślewska-Bednarek, M., Svatoš, A., Schneider, B., Doubský, J., Mansurova, M., Humphry, M., Consonni, C., Panstruga, R., SanchezVallet, A., Molina, A. and Schulze-Lefert, P. 2009. A glucosinolate metabolism pathway in living plant cells mediates broadspectrum antifungal defense. Science 323:101-106.

Berrocal-Lobo, M., Molina, A., and Solano, R. 2002. Constitutive expression of ETHYLENE-RESPONSE-FACTOR1 in Arabidopsis confers resistance to several necrotrophic fungi. Plant J. 29:23-32.

Bittel, P., and Robatzek, S. 2007. Microbe-associated molecular patterns (MAMPs) probe plant immunity. Curr. Opin. Plant Biol. 10:335-341.

Blakeney, N. B., Harris, P. J., Henry, R. J., and Stone, B. A. 1983. A simple and rapid preparation of alditol acetates for monosaccharide analysis. Carbohydr. Res. 182:291-299.

Boucher, C. A., Barberis, P. A., Trigalet, A. P., and Demery, D. A. J. 1985. Transposon mutagenesis of Pseudomonas solanacearum: Isolation of Tn5-induced virulent mutants. J. Gen. Microbiol. 131:2449-2457.

Chinchilla, D., Zipfel, C., Robatzek, S., Kemmerling, B., Nurnberger, T., Jones, J. D., Felix, G., and Boller, T. 2007. A flagellin-induced complex of the receptor FLS2 and BAK1 initiates plant defence. Nature, 448:497-500.

Dangl, J. L., and Jones, J. D. 2001. Plant pathogens and integrated defence responses to infection. Nature 411:826-833.

Denoux, C., Galletti, R., Mammarella, N., Gopalan, S., Werck, D., de Lorenzo, G., Ferrari, S., Ausubel, F. M. and Dewdney, J. 2008. Activation of defense response pathways by OGs and Flg22 elicitors in Arabidopsis seedlings. Mol. Plant 1:423-445.

Diener, A. C., and Ausubel, F. M. 2005. RESISTANCE TO FUSARIUM OXYSPORUM 1, a dominant Arabidopsis disease-resistance gene, is not race specific. Genetics 171:305-321.

Dubois, M., Gilles, D. A., Hamilton, J. K., Rebers P. A., and Smith, F. 1956. Colorimetric method of determination of sugars and related substances. Anal. Chem. 28:350-356. 
Ellis, C., and Turner, J. G. 2001. The Arabidopsis mutant cev1 has constitutively active jasmonate and ethylene signal pathways and enhanced resistance to pathogens. Plant Cell 13:1025-1033.

Ferrari, S., Galletti, R., Denoux, C., De Lorenzo, G., Ausubel, F. M., and Dewdney, J. 2008. Resistance to Botrytis cinerea induced in Arabidopsis by elicitors is independent of salicylic acid, ethylene, or jasmonate signaling but requires PHYTOALEXIN DEFICIENT3. Plant Physiol. 144:367-79.

Filisetti-Cozzi, T. M., and Carpita, N. C. 1991. Measurement of uronic acids without interference from neutral sugars. Anal. Biochem. 197:157-162.

Fridborg, I., Kuusk, S., Robertson, M., and Sundberg, E. 2001. The Arabidopsis protein SHI represses gibberellin responses in Arabidopsis and barley. Plant Physiol. 127:937-948.

Gibeaut, D. M., and Carpita, N. C. 1991. Tracing the biosynthesis of the cell wall in intact cells and plants: Selective turnover and alteration of soluble and cell wall polysaccharides in grasses. Plant Physiol. 97:551561.

Godiard, L., Sauviac, L., Torii, K. U., Grenon, O., Mangin, B., Grimsley, N. H., and Marco, Y. 2003. ERECTA, an LRR receptor-like kinase protein controlling development pleiotropically affects resistance to bacterial wilt. Plant J. 36:353-365.

Gomez-Gomez, L., Felix, G., and Boller, T. 1999. A single locus determines sensitivity to bacterial flagellin in Arabidopsis thaliana. Plant $\mathbf{J}$. $18: 277-284$

Gomez-Gomez, L., Bauer, Z., and Boller, T. 2001. Both the extracellular leucine-rich repeat domain and the kinase activity of FSL2 are required for flagellin binding and signaling in Arabidopsis. Plant Cell 13:11551163.

Guillemin, F., Guillon, F., Bonnin, E., Devaux, M. F., Chevalier, T., Knox, J. P., Liners, F., and Thibault, J. F. 2005. Distribution of pectic epitopes in cell walls of the sugar beet root. Planta 222:355-371.

Hara, K., Kajita, R., Torii, K. U., Bergmann, D. C., and Kakimoto, T. 2007. The secretory peptide gene EPF1 enforces the stomatal one-cellspacing rule. Genes Dev. 21:1720-1725.

He, K., Gou, X., Yuan, T., Lin, H., Asami, T., Yoshida, S., Russell, S. D. and $\mathrm{Li}, \mathrm{J} .2007$. BAK1 and BKK1 regulate brassinosteroid-dependent growth and brassinosteroid-independent cell-death pathways. Curr. Biol. 17:1109-1115.

Hématy, K., and Höfte, H. 2008. Novel receptor kinases involved in growth regulation. Curr. Opin. Plant Biol. 11:321-328.

Hématy, K., Sado, P. E., Van Tuinen, A., Rochange, S., Desnos, T. Balzergue, S., Pelletier, S., Renou, J. P., and Höfte, H. 2007. A receptorlike kinase mediates the response of Arabidopsis cells to the inhibition of cellulose synthesis. Curr. Biol. 17:922-931.

Hernández-Blanco, C., Feng, D. X., Hu, J., Sánchez-Vallet, A., Deslandes, L., Llorente, F., Berrocal-Lobo, M., Keller, H., Barlet, X., SánchezRodríguez, C., Anderson, L. K., Somerville, S., Marco, Y., and Molina, A. 2007. Impairment of cellulose synthases required for Arabidopsis secondary cell wall formation enhances disease resistance. Plant Cell, 19:890-903.

Humphrey, T. V., Bonetta, D. T., and Goring, D. R. 2007. Sentinels at the wall: Cell wall receptors and sensors. New Phytol. 176:7-21.

Jones, L., Seymour, G. B., and Knox, J. P. 1997. Localization of pectic galactan in tomato cell walls using a monoclonal antibody specific to (1[->]4)-[beta]-D-galactan. Plant Physiol. 113:1405-1412.

Kauráková M, Capek P, Sasinková V, Wellner N, and Ebringerová, A. 2000. FT-IR study of plant cell wall model compounds: Pectic polysaccharides and hemicelluloses. Carbohydr. Polym. 43:195-203.

Kemmerling, B., Schwedt, A., Rodríguez, P., Mazzotta, S., Frank, M., Qamar, S. A., Mengiste, T., Betsuyaku, S., Parker, J. E., Mussig, C., Thomma, B. P., Albrecht, C., de Vries, S. C., Hirt, H., and Nurnberger, T. 2007. The BRI1-associated kinase 1, BAK1, has a brassinolideindependent role in plant cell-death control. Curr. Biol. 17:11161122 .

Kemsley, E. K. 1996. Discriminant analysis of high-dimensional data: A comparison of principal components analysis and partial least squares data reduction methods. Chemometrics Intelligent Lab. Syst. 33:4761.

Lease, K. A., Lau, N. Y., Schuster, R. A., Torii, K. U., and Walker, J. C. 2001. Receptor serine/threonine protein kinases in signaling: Analysis of the ERECTA receptor-like kinase of Arabidopsis thaliana. New Phytol. $151: 133-144$

Li, J., Wen, J., Lease, K. A., Doke, J. T., Tax, F. E., and Walker, J. C. 2002. BAK1, an Arabidopsis LRR receptor-like protein kinase, interacts with BRI1 and modulates brassinosteroid signaling. Cell, 110:213-222.

Liners, F., Letesson, J. J., Didembourg, C., and Van Cutsem, P. 1989. Monoclonal antibodies against pectin: Recognition of a conformation induced by calcium. Plant Physiol. 91:1419-1424.

Llorente, F., Alonso-Blanco, C., Sánchez-Rodríguez, C., Jorda, L., and Molina, A. 2005. ERECTA receptor-like kinase and heterotrimeric G protein from Arabidopsis are required for resistance to the necrotrophic fungus Plectosphaerella cucumerina. Plant J. 43:165-180.

Masle, J., Gilmore, S. R., and Farquhar, G. D. 2005. The ERECTA gene regulates plant transpiration efficiency in Arabidopsis. Nature 436:866870 .

Mauch-Mani, B., and Mauch, F. 2005. The role of abscisic acid in plantpathogen interactions. Curr. Opin. Plant Biol. 8:409-414.

Mele, G., Ori, N., Sato, Y., and Hake, S. 2003. The knotted1-like homeobox gene BREVIPEDICELLUS regulates cell differentiation by modulating metabolic pathways. Genes Dev. 17:2088-2093.

Nishimura, M. T., Stein, M., Hou, B. H., Vogel, J. P., Edwards, H., and Somerville, S. C. 2003. Loss of a callose synthase results in salicylic acid-dependent disease resistance. Science, 301:969-972.

Nürnberger, T., and Brunner, F. 2002. Innate immunity in plants and animals: Emerging parallels between the recognition of general elicitors and pathogen-associated molecular patterns. Curr. Opin. Plant Biol. 5:318-324.

Osorio, S., Castillejo, C., Quesada, M. A., Medina-Escobar, N., Brownsey, G. J., Suau, R., Heredia, A., Botella, M. A., and Valpuesta, V. 2008. Partial demethylation of oligogalacturonides by pectin methyl esterase 1 is required for eliciting defence responses in wild strawberry (Fragaria vesca). Plant J. 54:43-55.

Philip, B., and Levin, D. E. 2001. Wsc1 and Mid2 are cell surface sensors for cell wall integrity signaling that act through Rom2, a guanine nucleotide exchange factor for Rho1. Mol. Cell Biol. 21:271-280.

Pillitteri, L. J., Bemis, S. M., Shpak, E. D., and Torii, K. U. 2007. Haploinsufficiency after successive loss of signaling reveals a role for ERECTA-family genes in Arabidopsis ovule development. Development 134:3099-3109.

Puhlmann, J., Bucheli, E., Swain, M. J., Dunning, N., Albersheim, P., Darvill, A. G., and Hahn, M. G. 1994. Generation of monoclonal antibodies against plant cell-wall polysaccharides. I. Characterization of a monoclonal antibody to a terminal alpha-(1-->2)-linked fucosyl-containing epitope. Plant Physiol. 104:699-710.

Reiter, W. D., Chapple, C., and Somerville, C. R. 1993. Altered growth and development in a fucose-deficient cell wall mutant of Arabidopsis. Science 261:1032-1035.

Shiu, S. H., Karlowski, W. M., Pan, R., Tzeng, Y. H., Mayer, K. F., and Li, W. H. 2004. Comparative analysis of the receptor-like kinase family in Arabidopsis and rice. Plant Cell, 16:1220-1234.

Shpak, E. D., Lakeman, M. B., and Torii, K. U. 2003. Dominant-negative receptor uncovers redundancy in the Arabidopsis ERECTA Leucinerich repeat receptor-like kinase signaling pathway that regulates organ shape. Plant Cell, 15:1095-1110.

Shpak, E. D., Berthiaume, C. T., Hill, E. J., and Torii, K. U. 2004. Synergistic interaction of three ERECTA-family receptor-like kinases controls Arabidopsis organ growth and flower development by promoting cell proliferation. Development 131:1491-1501.

Shpak, E. D., McAbee, J. M., Pillitteri, L. J., and Torii, K. U. 2005 Stomatal patterning and differentiation by synergistic interactions of receptor kinases. Science, 309:290-293.

Song, W. Y., Wang, G. L., Chen, L. L., Kim, H. S., Pi, L. Y., Holsten, T., Gardner, J., Wang, B., Zhai, W. X., Zhu, L. H., Fauquet, C., and Ronald, P. 1995. A receptor kinase-like protein encoded by the rice disease resistance gene, $\mathrm{Xa21}$. Science 270:1804-1806.

Stevenson, T., and Furneaux, R. 1991. Chemical methods for the analysis of sulphated galactans from red algae. Carbohydr. Res. 210:277-298.

Thomma, B. P., Eggermont, K., Tierens, K. F., and Broekaert, W. F. 1999. Requirement of functional ethylene-insensitive 2 gene for efficient resistance of Arabidopsis to infection by Botrytis cinerea. Plant Physiol. 121:1093-1102.

Torii, K. U., Mitsukawa, N., Oosumi, T., Matsuura, Y., Yokoyama, R., Whittier, R. F., and Komeda, Y. 1996. The Arabidopsis ERECTA gene encodes a putative receptor protein kinase with extracellular leucinerich repeats. Plant Cell 8:735-746.

Vogel, J., and Somerville, S. 2000. Isolation and characterization of powdery mildew-resistant Arabidopsis mutants. Proc. Natl. Acad. Sci. U.S.A. 97:1897-1902.

Vogel, J. P., Raab, T. K., Schiff, C., and Somerville, S. C. 2002. PMR6, a pectate lyase-like gene required for powdery mildew susceptibility in Arabidopsis. Plant Cell, 14:2095-2106.

Vogel, J. P., Raab, T. K., Somerville, C. R., and Somerville, S. C. 2004 Mutations in PMR5 result in powdery mildew resistance and altered cell wall composition. Plant J. 40:968-978.

Vorwerk, S., Somerville, S., and Somerville, C. 2004. The role of plant cell wall polysaccharide composition in disease resistance. Trends Plant Sci. 9:203-209.

Wagner, T. A., and Kohorn, B. D. 2001. Wall-associated kinases are expressed throughout plant development and are required for cell expansion. Plant Cell, 13:303-318. 
Wei, Y., Zhang, Z., Andersen, C. H., Schmelzer, E., Gregersen, P. L., Collinge, D. B., Smedegaard-Petersen, V., and Thordal-Christensen, H. 1998. An epidermis/papilla-specific oxalate oxidase-like protein in the defence response of barley attacked by the powdery mildew fungus. Plant Mol. Biol. 36:101-112.

Willats, W. G., Marcus, S. E., and Knox, J. P. 1998. Generation of monoclonal antibody specific to (1-->5)-alpha-L-arabinan. Carbohydr. Res. 308:149-152.

Willats, W. G., McCartney, L., Steele-King, C. G., Marcus, S. E., Mort, A., Huisman, M., van Alebeek, G. J., Schols, H. A., Voragen, A. G., Le Goff, A., Bonnin, E., Thibault, J. F., and Knox, J. P. 2004. A xylogalacturonan epitope is specifically associated with plant cell detachment. Planta 218:673-681.
Woodward, C., Bemis, S. M., Hill, E. J., Sawa, S., Koshiba, T., and Torii, K. U. 2005. Interaction of auxin and ERECTA in elaborating Arabidopsis inflorescence architecture revealed by the activation tagging of a new member of the YUCCA family putative flavin monooxygenases. Plant Physiol. 139:192-203.

Xu, S.-L., Rahman, A., Baskin, T. I., and Kieber, J. J. 2008. Two leucine-rich repeat receptor kinases mediate signaling linking cell wall biosynthesis and ACC synthase in Arabidopsis. Plant Cell 20:30653079 .

Zipfel, C., Kunze, G., Chinchilla, D., Caniard, A., Jones, J. D., Boller, T., and Felix, G. 2006. Perception of the bacterial PAMP EF-Tu by the receptor EFR restricts Agrobacterium-mediated transformation. Cell 125:749-760 